\title{
COMPETÊNCIAS NA FORMAÇÃO DE PROFESSORES: DA LDB À BNCC
}

\section{COMPETENCES ON TEACHER EDUCATION: FROM LDB TO BNCC}

\author{
G. O. MAQUINÉ'1,*, R. O. M. AZEVEDO1 \\ 1 Instituto Federal de Educação, Ciência e Tecnologia do Amazonas, Mestrado Profissional em \\ Ensino Tecnológico, Brasil.
}

\author{
ARTICLE INFO \\ Article history: \\ Received 2018-04-13 \\ Accepted 2018-04-30 \\ Available online 2018-05-02 \\ *Autor correspondente: \\ E-mail:gilmaramaquine@gmail.com
}

Palavras-chave: Competências. Formação de Professores. LDB. BNCC.

RESUMO. Este artigo elenca aspectos das competências na formação de professores encontrados desde a Lei de Diretrizes Bases da Educação (LDB) até a Base Nacional Comum Curricular (BNCC). O objetivo é evidenciar as competências em documentos que norteiam a educação no Brasil e os reflexos destas publicações na formação docente. A investigação foi conduzida na disciplina Fundamentos para a Formação de Professores no Ensino Tecnológico (Mestrado em Ensino Tecnológico no Instituto Federal do Amazonas). Está organizado em três seções, além da introdução e das considerações finais. A primeira seção apresenta conceituações de competências identificadas nas literaturas; a segunda destaca os aspectos de competências identificados na LDB; a terceira aponta as características de competências na BNCC. Os resultados do estudo indicam que existe uma tendência na discussão de competências para a formação de professores que requer a necessidade de discussão aprofundada sobre a temática, em particular, considerando a publicação da BNCC.

\begin{abstract}
This article aspects of competences in teacher education found since Education Law Bases of Education (LDB) from National Common Curricular Base to Brazilian education (BNCC). The purpose is point the competencies into documents that guide the education on Brazil and the reflexes of this on teacher education. The investigation was conducted in the discipline Fundamentals for Teacher Education in Technology Teaching of Professional Master's in Technology Teaching - MPET of Federal Institute of Education, Science and Technology of Amazonas State. It is organized into three sections, beyond introduction and final considerations. The first presents conceptualization of competencies identified in literature; the second highlights the competency aspects identified in LDB; the third points out the characteristics of competences in BNCC; $t$. The results of the study indicate that there is a tendency in the discussion of competences for teacher training as well as the need for in-depth discussion on the subject considering the publication of the BNCC.
\end{abstract}

\section{INTRODUÇÃO}

No Brasil, as discussões acerca das competências na formação de professores têm início em meados de 1990. Holanda, Freres e Gonçalves (2009) afirmam que o termo competências fortificouse nesta década, principalmente em decorrência das reformas educacionais ocorridas no Brasil, com o objetivo de atender as demandas do mundo do trabalho.

Neste sentido, a Lei de Diretrizes Bases da Educação (LDB), publicada em 1996, apresenta em seu contexto diversas características que apontam para a utilização das competências na 
formação dos professores e, nesse aspecto, podemos destacar a sua publicação como um marco para a educação brasileira. A Base Nacional Comum Curricular (BNCC), publicada pelo Ministério da Educação (MEC) em 2017, evidencia que as competências norteiam as ações previstas para a educação básica no Brasil, assim como o desenvolvimento de habilidades e conhecimentos específicos. Roque, Elia e Motta (2004) afirmam que na LDB, 1996, nos Parâmetros Nacionais Curriculares (PCN) e em textos da reforma do Ensino médio, conseguimos identificar a necessidade de focar o ensino-aprendizagem em uma relação entre conteúdos, competências e habilidades e finalizam que é necessário pensar para além do ensino propedêutico.

Em vista do exposto, este estudo tem como principal objetivo elencar características de competências encontradas nos documentos que norteiam a formação de professores na educação brasileira, desde LDB até a BNCC, e com isto trazer a discussão para o contexto atual. O estudo foi conduzido por meio da pesquisa bibliográfica realizada durante a disciplina Fundamentos para a Formação de Professores no Ensino Tecnológico (Mestrado em Ensino Tecnológico no Instituto Federal do Amazonas), a partir de resumos e fichamentos de trabalhos relacionados à temática, em livros, periódicos e dissertações. Está organizado em três seções, sendo elas: Conceituação de Competências; Competências na LDB e Competências na BNCC. Esperamos que este trabalho evidencie a discussão necessária acerca de competências na formação de professores, considerando toda a trajetória documentada nas leis e diretrizes nacionais, e percorrida até o presente.

\section{CONCEITUAÇÃO DE COMPETÊNCIAS}

A conceituação do termo competências vem sendo discutida, se considerarmos que nas diversas áreas/campos de conhecimentos podem ser identificadas diversas ramificações. Neste sentido, vamos abordar as conceituações relativas à educação e à formação de professores.

Perrenoud (2000, p. 15) conceitua competências como "[...] a capacidade de mobilizar diversos recursos cognitivos para enfrentar um tipo de situação", ou seja, o conceito aqui disposto está associado à capacidade de reunir e utilizar conhecimentos para enfrentamento de determinadas situações. Para que possamos entender a conceituação proposta, o autor afirma que é necessário destacar alguns aspectos:

1. As competências não são elas mesmas saberes, savoir-faire ou atitudes, mas mobilizam, integram e orquestram tais recursos. 2. Essa mobilização só é pertinente em situação, sendo cada situação singular, mesmo que se possa tratá-la em analogia com outras, já encontradas. 3 . O exercício da competência passa por operações mentais complexas, subentendidas por esquemas de pensamento (Altet, 1996; Perrenoud, 1996l, 1998g), que permitem determinar (mais ou menos consciente e rapidamente) e realizar (de modo mais ou menos eficaz) uma ação relativamente adaptada à situação. 4. As competências profissionais constroem-se, em formação, mais também ao sabor da navegação diária de um professor, de uma situação de trabalho à outra (LE BOTERF, 1997 apud PERRENOUD, 2000, p. 15).

Em seus estudos, Perrenoud (2000) apresenta dez competências para ensinar, listadas a seguir, para operacionalizar o trabalho docente:

1. Organizar e dirigir situações de aprendizagem; 2. Administrar a progressão das aprendizagens; 3 . Conceber e fazer evoluir os dispositivos de diferenciação; 4. Envolver os alunos e suas aprendizagens e em seu trabalho; 
5. Trabalhar em equipe; 6. Participar da administração da escola;7. Informar e envolver os pais; 8. Utilizar novas tecnologias; 9. Enfrentar os deveres e os dilemas éticos da profissão; 10. Administrar a própria formação contínua. (PERRENOUD, 2000, p.14).

Rios (2008, p.78) compreende a definição de competências, explicitada por Perrenoud, como "[...] capacidades que se apoiam em conhecimentos. [...]". A abordagem da autora, inicia com uma diferenciação entre os termos competência e competências. Para a autora, o termo competência está associado ao sentido da ação, ou seja, ao saber fazer, como afirma: "Na verdade, ela se refere sempre a um fazer que requer um conjunto de saberes e implica um posicionamento diante daquilo que se apresenta como desejável e necessário." (RIOS, 2008, p. 88).

Já o termo competências, no campo da educação, substitui alguns termos, sendo eles: "saberes", "habilidades", "capacidades" e etc. e no espaço do trabalho assume o significado de "qualificação". (RIOS, 2008).. É importante ressaltar também que Rios (2008) traz uma crítica ao uso do termo competências e o seu entendimento, a saber:

Meu intuito não é o de me contrapor, pura e simplesmente, à utilização do termo 'competências', indicando sua inadequação. Na verdade, a referência às competências, no âmbito das propostas de alguns teóricos, parece indicar um movimento no sentido de dar maior flexibilidade à formação, rompendo com modelos fechados de saberes e disciplinas. Entretanto, quando apropriada pelas propostas oficiais, percebe-se que corre o risco de apenas atender a uma nova moda, mantendo-se no discurso, uma vez que não se têm alterado as condições concretas do contexto educacional. (RIOS, 2008, p. 85).

Altet (2001) entende por "competência profissional" o conjunto de conhecimentos, saber-fazer e posturas, mas também ações e as atitudes necessárias ao exercício da profissão. Roque, Elias e Motta (2004) afirmam que as características da Pedagogia das competências podem embasar tanto a educação na modalidade presencial quanto na a distância. Para tanto, afirmam que:

A definição de competência como a capacidade do sujeito de mobilizar os recursos necessários para o enfrentamento de novas situações e a consequente mobilização de suas estruturas conceituais está em estreita relação com algumas características da Educação a Distância (EAD) [...] (ROQUE; ELIAS; MOTTA, 2004, p. 101).

Em seu estudo, Starepravo (2009) apresenta a definição de competência a partir do dicionário, fazendo um recorte para o mundo educacional onde o aspecto da mobilização de conhecimentos e das habilidades é de suma importância. Segundo o autor, "a ideia de competência está mais ligada ao que o indivíduo é capaz de fazer a partir do que possui. Competência implica, então, fazer escoIhas, decidir, mobilizar recursos e agir" (STAREPRAVO, 2009, p. 4).

Gaspar (2004) afirma que no contexto educacional fica evidente a necessidade de conceituar competência no sentindo de desmistificar alguns sinônimos para a palavra. Destacam-se quatro palavras que são frequentemente utilizadas como sinônimos: (1) objetivo; (2) habilidade; (3) aptidão; (4) capacidade. Nesse sentido, Dias afirma que o conceito de competência "[...] integra e coordena um conjunto de esquemas (de percepção, pensamento, avaliação e ação) que sustém inferências, antecipações, transposições analógicas, generalizações, probabilidades, recolha de informação pertinente,tomada de decisão" (2010, p. 75). 
Muito embora, até o momento, tenhamos identificado que o termo competência (s) possui diferentes conceituações, Font, Breda e Sala (2015) apresentam algumas características associadas à noção de competências, sendo elas:

1) Serve para e se manifesta mediante a ação; 2 ) Se mostra através do desenvolvimento pessoal e social; 3) Sempre se refere a um contexto de aplicação; 4) Apresenta caráter integrador, já que implica na integração do conhecimento teórico conceitual e procedimental; 5) Possibilidade de transferência a diferentes situações ou problemas; 6) Caráter dinâmico, o que implica um desenvolvimento gradual da competência (FONT; BREDA; SALA, 2015, p. 21).

Diante do exposto, podemos perceber que o conceito de competências vem sendo discutido e converge muito fortemente para proposição de Perrenoud (2000), no que se refere à mobilização de conhecimentos, habilidades para resolver uma determinada situação. Na próxima seção vamos discorrer sobre estes conceitos e características identificadas na Lei de Diretrizes Bases (LDB) e como esta reflete na formação de professores.

\section{COMPETÊNCIAS NA LDB}

O conceito de competências relacionado à formação de professores no Brasil pode ser evidenciado na Lei de Diretrizes Bases da Educação (LDB), Lei oㅜ 9.394, de 20 de dezembro de 1996, como núcleo na organização curricular (DIAS, LOPES, 2003). No Artigo 9ำ da LDB o Inciso IV, é possível identificar o termo competências como responsabilidade que cabe a União: [...] estabelecer, em colaboração com os Estados, o Distrito Federal e os Municípios, competências e diretrizes para a Educação Infantil, o Ensino Fundamental e o Ensino Médio, que nortearão os currículos e seus conteúdos mínimos, de modo a assegurar formação básica comum (BRASIL, 1996). Grifo nosso).

Ainda na LDB, o artigo no 61 detalha que "A formação de profissionais da educação, de modo a atender aos objetivos dos diferentes níveis e modalidades de ensino e às características de cada fase do desenvolvimento do educando [...]" (BRASIL, 1996). Neste sentindo, Fernandes (2009) afirma que o movimento de reformas educacionais, nos anos 90 , foi motivado por diversas organizações internacionais, tais como: Organização para a Cooperação e o Desenvolvimento Econômico (OCDE), União Europeia, UNESCO e outras. Descreve, ainda, que essas reformas foram realizadas em decorrência da necessidade de "adequar" o sistema educacional a demandas de mercado de trabalho. Com a publicação da nova LDB, segundo aponta Carvalho (1998), ocorreu uma divisão histórica na LDB em dois momentos: o primeiro composto por debates entre governo e representantes das entidades educacionais e o segundo relacionado a orientação da política educacional do governo.

Ribas, Perito, Armoni e Junior (2006) pautam a discussão sobre competência no exercício do magistério a partir da consideração de que existem diferentes discussões acerca de competências. Complementam ainda que a LDB e as Diretrizes Curriculares Nacionais (DCNs): "aponta para a necessidade de mudanças que permitam transformar o perfil do profissional, rompendo com propostas curriculares anteriores, tais como: currículos lineares que desenvolviam conteúdos estanques e a fragmentação do eixo de formação" (RIBAS; PERITO; ARMONI; JUNIOR, 2006, p. 44). 
Dias e Lopes (2003, p. 1156) destacam ainda, que muito embora exista a dificuldade de conceituar competências, nos documentos ministeriais brasileiros para a formação de professores estas são definidas de maneira direta e clara. Um desses documentos que norteiam a formação de professores, entre o período de 1999 a 2001, é o Referencial para Formação de Professores (RFP) qual apresenta o conceito de competências: [...] o conceito de competência profissional defendido neste documento - que pressupõe a capacidade de mobilizar saberes de diferentes naturezas no exercício de suas funções e segundo o qual a real qualidade do trabalho profissional só pode ser aferida em situação contextualizada. (BRASIL, 1999, p. 61).

A afirmação anterior é corroborada por Cordão (2009) ao afirmar que embora o conceito de competência profissional receba diferentes significados, as Diretrizes Nacionais Curriculares definem de maneira clara, e complementa que o Conselho Nacional de Educação

[...] desenvolve, mobiliza e articula, holística e integradamente os seus saberes, em termos de conhecimentos, habilidades, atitudes, valores e emoções, absolutamente necessários para a resolução de problemas não só rotineiros, mas também inusitados em seu campo de atuação profissional e no dia-a-dia de sua vida pessoal e coletiva como cidadão-trabalhador (CORDÃO, 2009, p. 18).

As Diretrizes Curriculares Nacionais para a Formação de Professores da Educação Básica (DCNFP), publicadas em 2001, trazem para o cenário de formação de professores a seguinte conceituação de competências:

As competências tratam sempre de alguma forma de atuação, só existem "em situação" e, portanto, não podem ser aprendidas apenas no plano teórico nem no estritamente prático. A aprendizagem por competências permite a articulação entre teoria e prática e supera a tradicional dicotomia entre essas duas dimensões, definindo-se pela capacidade de mobilizar múltiplos recursos numa mesma situação, entre os quais os conhecimentos adquiridos na reflexão sobre as questões pedagógicas e aqueles construídos na vida profissional e pessoal, para responder às diferentes demandas das situações de trabalho (BRASIL, 2001, p. 29).

As Diretrizes Curriculares Nacionais para a Educação Básica (DCN), com publicação em 2013, têm o objetivo de estabelecer a base nacional comum e organizar a articulação das propostas pedagógicas das redes de ensino brasileira. No Capítulo IV o artigo 57 destaca a valorização do profissional da educação, e evidenciamos o Inciso $2^{\circ}$ :

$\S 2^{\circ}$ Os programas de formação inicial e continuada dos profissionais da educação, vinculados às orientações destas Diretrizes, devem prepará-los para o desempenho de suas atribuições, considerando necessário: a) além de um conjunto de habilidades cognitivas, saber pesquisar, orientar, avaliar e elaborar propostas, isto é, interpretar e reconstruir o conhecimento coletivamente; b) trabalhar cooperativamente em equipe; c) compreender, interpretar e aplicar a linguagem e os instrumentos produzidos ao longo da evolução tecnológica, econômica e organizativa; d) desenvolver competências para integração com a comunidade e para relacionamento com as famílias (BRASIL, 2013, p.78). Grifos nossos

Andrade (2015) destaca que o Brasil, seguindo um movimento mundial, aderiu à tendência de competências e as introduziu em sua reforma educacional. Destaca, ainda, que os primeiros indícios 
são identificados nos Parâmetros Curriculares Nacionais (PCN), que foram publicados em 1997, para complementação a LBD, porém, somente consolidados no Plano Decenal de Educação, no qual pode ser identificado:

No Plano é possível verificar os primeiros passos do compromisso brasileiro com um ensino por competências, destacando competências comunicativas, cognitivas, sociais atendendo aos objetivos de Jomtien, que é de satisfazer as necessidades básicas de aprendizagem e a provisão de competências fundamentais requeridas para a participação plena na vida do país, as quais se dividem em cognitivas e sociais (ANDRADE, 2015, p.160).

Desta maneira, é possível identificar que a partir da publicação da LDB, em 1996, fez-se necessário a realização de adequações na formação de professores para atender a necessidade explicitada na Lei, e neste sentido foram criados documentos que norteiam a formação docente baseados em competências, sendo alguns deles: RFP, DCN. Nota-se, ainda, que a pedagogia por competências já vinha sendo pautada na LDB e que os documentos foram criados com o objetivo de atender a necessidade exposta.

$\mathrm{Na}$ próxima seção serão abordados os aspectos identificados na BNCC quanto a competências, uma vez que a partir de sua publicação, no final de 2017, as instituições de ensino têm até 2020 para adequarem seus currículos para atender as necessidades descritas neste documento.

\section{COMPETÊNCIAS NA BNCC}

A Base Nacional Comum Curricular (BNCC) foi aprovada e homologada pelo Ministério da Educação, em dezembro de 2017, porém, o processo de construção deste documento foi iniciado em meados de 2015 e com isto iniciam-se também as discussões acerca da formação de professores que atendam a este novo cenário. Na BNCC, competência é definida como: [...] a mobilização de conhecimentos (conceitos e procedimentos), habilidades (práticas, cognitivas e socioemocionais), atitudes e valores para resolver demandas complexas da vida cotidiana, do pleno exercício da cidadania e do mundo do trabalho (BRASIL, 2017, p. 8).

A BNCC para o Ensino Fundamental e Ensino médio, mostra que a responsabilidade por adequações necessárias à formação docente cabe à União, conforme destacado a seguir:

A primeira tarefa de responsabilidade direta da União será a revisão da formação inicial e continuada dos professores para alinhá-las à BNCC. A ação nacional será crucial nessa iniciativa, já que se trata da esfera que responde pela regulação do ensino superior, nível no qual se prepara grande parte desses profissionais. Diante das evidências sobre a relevância dos professores e demais membros da equipe escolar para o sucesso dos alunos, essa é uma ação fundamental para a implementação eficaz da BNCC (BRASIL, 2017 - 2018, p. 21).

Neste sentido, o Ministério da Educação (MEC), em outubro de 2017, lançou a Política Nacional de Formação de Professores, que tem objetivo de acolher os princípios estabelecidos na Constituição Federal, na LDB, no PNE entre outros documentos. Na apresentação foram divulgadas as ações previstas para a formação docente, como por exemplo, Base Nacional Docente e ampliação da qualidade e acesso a formação continuada. A Base Nacional Docente norteará o currículo para formação de professores, cuja elaboração deverá ser articulada com estados e municípios e será 
levada a consulta pública em 2018. (MEC, 2017). Santos e Pereira (2016) fazem críticas ao que chamam de tentativa da padronização de currículos com a publicação da BNCC. Segundo os autores,

A proposta de uma BNCC termina sendo uma medida inócua, pois a experiência tem mostrado que os professores, com raras exceções, não consultam os documentos oficiais para preparar suas aulas. Outras medidas são necessárias para elevar o padrão de qualidade da educação brasileira, que incluem desde a melhoria dos prédios e equipamentos escolares até a melhoria da carreira, do salário e da formação dos professores. Docentes bem qualificados são indispensáveis para a democratização da educação, contribuindo para que as crianças e jovens das camadas populares possam ter uma trajetória escolar mais longa e sem grandes percalços (SANTOS; PEREIRA, 2016, p. 288).

Andrade (2015), em sua dissertação de mestrado, destaca o desafio na formação por competências, salientando que o primeiro ponto é relacionar diretamente a formação com o desenvolvimento das competências profissionais:

[...] o desafio na formação por Competências, é, primeiramente, o de colocar explicitamente a formação contínua a serviço do desenvolvimento das competências profissionais. Algumas modalidades de reciclagem ou aperfeiçoamento ampliam a cultura, a informação ou os talentos artesanais ou técnicos dos professores. Pode-se esperar que isso desenvolva também suas competências profissionais, mas caberá ao interessado inscrever esses aportes em uma perspectiva pedagógica e didática (ANDRADE, 2015, p. 279).

Marchelli (2017) afirma que a BNCC trará mudanças para a formação inicial dos professores e propõe a seguinte questão: "quais serão as novas propostas dos projetos pedagógicos dos cursos de licenciatura decorrentes dos pressupostos trazidos da Base e como isso impactará a formação inicial de professores?". O autor completa afirmando que a possibilidade da abertura e adequação dos projetos pedagógicos à BNCC parece pouco provável. Ao final de seu trabalho afirma, veementemente, que em decorrência das estreitas relações com os cursos de licenciatura.

[...] a BNCC impactará de maneira marcante os cursos de licenciatura, que de fato precisam encontrar urgentemente novos rumos para se organizarem. O princípio da desfragmentação e tratamento interdisciplinar do conhecimento é apresentado de forma precípua na Base e passa a ser colocado às políticas de formação como parte integrante dos procedimentos que devem ser adotados para a gestão dos programas, planejamento, processos de avaliação e regulação das instituições formadoras (MARCHELLI, 2017, p. 67).

A Comissão Permanente de Formação de Professores (CPFP) da Unicamp (2017) divulgou sua manifestação acerca da publicação da BNCC, e neste documento a argumentação da Comissão traz ponderações, preocupações e posicionamentos para discussão acerca da BNCC. Neste sentido, a CPFP reconhece a importância do alinhamento da BNCC com o Plano Nacional da Educação. Ressalta também os seguintes pontos para a formação de professores

[...]. i. A formação continuada de professores será cada vez mais submetida às definições da Base e aos resultados de avaliações padronizadas, sem levar em conta o sujeito-professor e sua interlocução com o ambiente em que atua, e que auxilia na construção crítica e reflexiva. j. A formação inicial de professores será progressivamente pautada por diretrizes padronizadas 
que não levam em conta iniciativas de formação diferenciadas ou quaisquer projetos que sejam fruto do questionamento e da proposição de alternativas aos modos tradicionais de se educar, e/ou políticas emancipatórias de formação (UNICAMP, 2017, p. 6).

Com o exposto, nesta seção, foi possível evidenciar como a BNCC apresenta as competências e quais os possíveis reflexos para a formação docente.

\section{CONSIDERAÇÕES FINAIS}

O termo competências pode assumir diferentes conceituações, porém é possível identificar algumas características comuns quando aplicado ao contexto da educação/formação de professores. Os autores referenciados neste trabalho divergem em alguns aspectos e proporcionam uma discussão crítica acerca da temática. Foi possível evidenciar a concepção e desenvolvimento do termo competências, e suas características, em documentos que norteiam a educação brasileira, desde a LDB até a BNCC.

Neste sentido, as características identificadas na LDB são o ponto vital para a criação de outros documentos, tomados como bases para a formação de professores, tais como, referencias para a formação de professores (RFP) e Diretrizes Curriculares Nacionais para a Formação de Professores da Educação Básica. Já, a BNCC, por se tratar de um documento recente, ainda apresenta poucos aspectos pensados para a formação de professores, porém a criação da Política Nacional de Formação de Professores pode ser um caminho para o desenvolvimento da formação docente. Em síntese, na Figura 2, estão dispostos os marcos documentais das discussões do conceito de competências no Brasil,identificados neste estudo.

\section{Figura 2 - Marcos documentais das discussões do conceito de competências no Brasil}

\begin{tabular}{ccccc}
1996 & & 2001 & & 2017 \\
(LDB) & & (DNCF) & & (BNCC) \\
\hline & 0 & 0 & 0 & 0 \\
& 1999 & & 2013 & \\
& (RFP) & & (DCN)
\end{tabular}

Fonte: As autoras.

Ainda assim, é possível questionar se a Política Nacional de Formação de Professores abrange e articula o conceito de competências na formação de professores, de modo a pensar na melhoria desta formação, articulando essa com a prática docente.

\section{REFERÊNCIAS}

ANDRADE, M. do C. F. A formação de Professores para o Ensino Profissional e Tecnológico mediado pela metodologia por competências - a partir dos anos 70. Manaus, 2015. 268 f. Dissertação (Mestrado em Ensino Tecnológico) - Instituto Federal de Educação, Ciência e Tecnologia do Amazonas. 
content/uploads/2015/05/DISSERTA\%C3\%87\%C3\%83O-MARIA-DO-CARMO.pdf>. Acesso em: 5 abr. 2018.

ALTET, M. As competências do professor profissional: entre conhecimentos, esquemas e ação e adaptação, saber analisar. In: PAQUAY, L. et al (Org). Formando Professores Profissionais: Quais estratégias? Quais competências? Porto Alegre: Artmed Editora, 2001. p. 23-35.

BRASIL. Lei no 9.394, 20 de dezembro de 1996. Estabelece as diretrizes e bases da educação nacional. Diário Oficial [da] República Federativa do Brasil, Brasília, DF, 20 dez. 1996. Disponível em: <http://www.planalto.gov.br/Ccivil_03/leis/L9394.htm >. Acesso em: 4 abr. 2018.

BRASIL. Diretrizes Curriculares Nacionais para a Formação de Professores da Educação Básica, em nível superior, curso de licenciatura, de graduação plena. Brasília, DF: MEC, 2001.

BRASIL. Diretrizes Curriculares Nacionais da Educação Básica. Brasília: MEC, 2013.

BRASIL. Base Nacional Comum Curricular. Brasília: MEC, 2017.

BRASIL. Ministério de Educação e do Desporto. Secretaria de Educação Fundamental. Referenciais para a formação de professores. Brasília, DF: MEC/SEF, 1999.

CARVALHO, D. P. de. A Nova Lei de Diretrizes e Bases e a formação de professores para a educação básica,Ciênc. educ., v.5, n.2, 1998. Disponível em: <http://www.scielo.br/pdf/ciedu/v5n2/a08v5n2>. Acesso em: 4 abr. 2018.

CORDÃO, F. A. Desafios e tendências da Educação Profissional no Brasil - O desenvolvimento de competências profissionais deve proporcionar condições de laborabilidade, Revista Aprendizagem, v.12, n. 1, p. 60-62, 2009.

DIAS, E. R, LOPES, A. C. Competências na formação de professores no Brasil: o que (não) há de novo, Educ. Soc., v.24, n.85, 2003. Disponível em: <http://www.scielo.br/pdf/es/v24n85/a04v2485>. Acesso em: 27 mar. 2018.

DIAS, I. S. Competências em Educação: conceito e significado pedagógico, Revista Semestral da Associação Brasileira de Psicologia Escolar e Educacional, v.14, n.1, 2010, p.73-78.

FERNANDES, D. De que estamos realmente falando quando dizemos que estamos avaliando competências?,Revista Aprendizagem, v.12, n. 1, p. 42-23, 2009.

FONT, V.; BREDA, A.; SALA, G. Competências profissionais na formação inicial de professores de matemática, Práxis Educacional, v.11, n.19, p. 17-34, 2015.

GASPAR, M. I; Competências em questão: contributo para a formação de professores, Discursos em linha: perspectivas em educação, v.1, n.2, p. 55-71, 2004.

HOLANDA, F. H. de O.; FRERES, H.; GONCALVES, L. P. A pedagogia das competências e a formação de professores: breves considerações, Revista Eletrônica Arma da Crítica, v.1, n.1, p. 122-135, 2009.

MARCHELLI, P. S. Base Nacional Comum Curricular e formação de professores: o foco na organização interdisciplinar do ensino aprendizagem, Revista de Estudos de Cultura, n. 7, 2017.

MEC. MEC lança Política Nacional de Formação de Professores com Residência Pedagógica. Brasília, DF, 18 out. 2017. Disponível em: <http://portal.mec.gov.br/ultimas-noticias/211218175739/55921-mec-lanca-politica-nacional-de-formacao-de-professores-com-80-milvagas-para-residencia-pedagogica-em-2018> . Acesso em: 04 abr. 2018. 
PERRENOUD, P. Dez Novas Competências para Ensinar. Porto Alegre: Artmed, 2000.

RIBAS, T. R. C.; PERITO, M.; ARMONI, G. S.; JUNIOR, S. G. As diferentes dimensões da "competência" na formação do profissional-professor, Revista Educação, v.1, n.2, p.43-49, 2006.

RIOS, T. A. Compreender e Ensinar: por uma docência da melhor qualidade, 7 ed., São Paulo: Cortez, 2008.

ROQUE, G. O.; ELIA, M.; MOTTA, C. L. R. da. Uma ferramenta para avaliação de competência baseada em desenvolvimento de projeto. In: SIMPÓSIO BRASILEIRO DE INFORMÁTICA NA EDUCAÇÃO, 9., 2004, Manaus. Anais eletrônicos... Manaus: UFAM, 2004. p.100-109. Disponível em: <http://www.br-ie.org/pub/index.php/sbie/article/view/311/297> . Acesso em: 20 mar. 2018.

SANTOS, L. L. de C. P; PEREIRA, J. E. D. Tentativas de Padronização do Currículo e da Formação de Professores no Brasil, Cad. Cedes, v. 36, n. 100, p. 281-300, 2016.

STAREPRAVO, A. R. Raciocínio lógico - Uma competência transversal a ser desenvolvida na escola, Revista Aprendizagem, v.12, n. 1, p. 18-19, 2009.

UNICAMP. Comissão Central de Graduação. Comissão Permanente de Formação de Professores. Manifestação da Comissão Permanente de Formação de Professores da Unicamp sobre a elaboração da Base Nacional Comum Curricular. Campinas, 2017. 